\title{
Optimal Management of Patients with Advanced or Metastatic Cholangiocarcinoma: An Evidence-Based Review
}

\section{Dina loffe* \\ Pooja Phull* \\ Efrat Dotan}

Department of Medical Oncology, Fox Chase Cancer Center, Philadelphia, PA, USA

*These authors contributed equally to this work
Correspondence: Efrat Dotan

Department of Medical Oncology, Fox

Chase Cancer Center, 333 Cottman Ave,

Philadelphia, PA, I9III, USA

$\mathrm{Tel}+\mathrm{I} 2$ I5-728-2500

Email efrat.dotan@fccc.edu

\begin{abstract}
Cholangiocarcinomas are rare tumors originating at any point along the biliary tree. These tumors often pose significant challenges for diagnosis and treatment, and often carry a poor prognosis. However, in recent years, studies have identified significant molecular heterogeneity with up to $50 \%$ of tumors having detectable mutations, leading to the guideline recommendations for molecular testing as part of the diagnostic workup for these tumors. In addition, better classification of these tumors and understanding of their biology has led to new drugs being approved for treatment of this resistant tumor. This manuscript will provide a comprehensive review of the epidemiology, risk factors, diagnostic approach, molecular classification, and treatment options for patients with advanced cholangiocarcinomas.
\end{abstract}

Keywords: cholangiocarcinoma, chemotherapy, targeted therapy, molecular, detectable mutations

\section{Introduction}

Cholangiocarcinomas (CCA) are a rare, heterogeneous group of malignancies originating from biliary tract epithelium. They can emerge at any point along the biliary tree and are classified accordingly as intrahepatic or extrahepatic depending on their anatomical location. Intrahepatic cholangiocarcinomas (iCCA) are located within the hepatic parenchyma proximal to segmental bile ducts, while extrahepatic cholangiocarcinomas (eCCA) can occur anywhere along the extrahepatic bile duct (Figure 1). ${ }^{1}$ Although these tumors differ in clinical presentation and staging, they are generally aggressive and most often diagnosed in advanced stages, resulting in a very poor prognosis.

\section{Epidemiology and Risk Factors}

Cholangiocarcinomas represent about $3 \%$ of gastrointestinal malignancies in the United States, with approximately $1-2$ cases per $100,000 .^{2}$ Incidence of CCA varies throughout the world, reflecting the geographic distribution of risk factors. In the US and Europe, the main identifiable risk factors are fibropolycystic disease (e.g., choledochal cysts) and Primary Sclerosing Cholangitis (PSC). In Asia, the leading identifiable cause is chronic infection with liver flukes. Other identified risk factors include hepatolithiasis, chronic liver disease (e.g., viral hepatitis, cirrhosis), alcohol, smoking, obesity, fatty liver disease, diabetes, inflammatory bowel disease, and certain toxic exposures (e.g., dioxin, thorotrast). Several genetic conditions have 


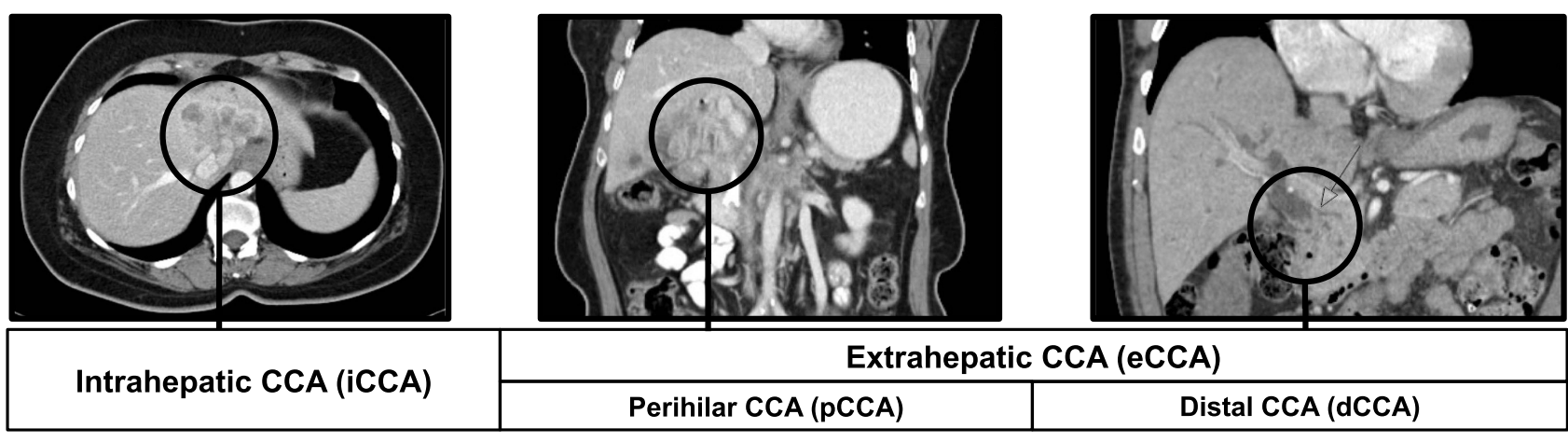

Figure I Cholangiocarcinoma subtypes.

also been associated with CCA, including Lynch syndrome, BAP-1 tumor predisposition syndrome, cystic fibrosis, and biliary papillomatosis. However, a specific risk factor cannot be identified in approximately $90 \%$ of patients with $\mathrm{CCA}^{3-8}$

CCA is more common in men than women, which may be associated with the higher incidence of PSC in men. In PSC patients, CCA is generally diagnosed at a younger age (30-50 years) and is often unresectable. ${ }^{9}$ Otherwise, the incidence generally increases with age with the average age of diagnosis between ages $60-70 .{ }^{10,11}$ Surveillance, Epidemiology, and End Results program (SEER) data have shown a slight increase in the incidence of eCCA and a dramatic increase in the incidence of iCCA $(4.4 \%$ over the last decade), which has also been noted across North America, Europe, Asia, and Australia over the last 20 years. $^{12,13}$ This may be due to changes in classification and increases in certain risk factors. Some have suggested this trend reflects improvements in diagnosis. However, there has not been a corresponding increase in diagnosis of smaller lesions or earlier stage disease; rather, mortality rates have been increasing worldwide., 5

\section{Tumor Subtypes}

About $90 \%$ of CCAs are extrahepatic (50\% perihilar, $40 \%$ distal) and 10\% are intrahepatic. Perihilar tumors (pCCA), also known as Klatskin tumors, occur at or near the confluence of the right and left hepatic ducts, and are the most common type of CCA. Distal cholangiocarcinomas (dCCA) occur along the common bile duct and proximal to the ampulla of Vater. Intrahepatic CCA is further classified by morphologic subtypes, which reflect the tumor growth pattern - mass forming, periductal, intraductal, or mixed. ${ }^{14,15}$ Histologically, over $90 \%$ of CCAs are adenocarcinomas. ${ }^{1,16,17}$ Rare histological variants include mucinous, adenosquamous, squamous, clear cell, sarcomatoid, and lymphoepithelial carcinomas (Table 1). ${ }^{18}$

\section{Clinical Presentation, Diagnosis, Challenges, and Prognosis}

Diagnosis of CCA is clinically challenging due to its anatomic location. In its early stages, CCA is usually asymptomatic and generally found due to abnormal liver function tests or incidentally on imaging as an isolated intrahepatic mass. Once symptoms occur, they are usually non-specific or related to biliary obstruction, at which point nearly $70 \%$ of patients have unresectable, locally advanced, or metastatic disease. ${ }^{19,20}$

Patients with eCCA generally present with symptoms of biliary obstruction, such as jaundice, pruritus, dark urine, and clay-colored stool. Abdominal pain, hepatomegaly, weight loss, and fever are also common signs and symptoms. In contrast, patients with iCCA often present late with non-specific symptoms, such as weight loss and dull right upper quadrant abdominal pain; biliary obstruction and associated symptoms are uncommon as these tumors do not usually involve the common bile duct. Metastasis usually occurs in local lymph nodes, the peritoneum, and liver. Less commonly, CCA can metastasize to the lungs and bone. ${ }^{21}$ Brain metastases have also been reported with $\mathrm{CCA}$, though they are very rare. ${ }^{21,22}$

Initial workup includes liver function tests, which usually have a cholestatic pattern with elevated bilirubin, alkaline phosphatase, and gamma-glutamyltransferase. Carcinoembryonic antigen (CEA) and carbohydrate antigen 19-9 (CA 19-9) levels should be obtained as a baseline; however, these are non-specific and are not used to confirm the diagnosis. Moreover, CA 19-9 may be falsely elevated in the setting of jaundice. ${ }^{23}$ Used together, these tumor markers can be helpful for monitoring treatment effect. 
Table I Features of Subtypes of Cholangiocarcinoma

\begin{tabular}{|c|c|c|c|}
\hline \multirow[t]{2}{*}{ Feature } & \multirow[t]{2}{*}{ Intrahepatic Cholangiocarcinoma (iCAA) } & \multicolumn{2}{|c|}{ Extrahepatic Cholangiocarcinoma (eCCA) } \\
\hline & & Perihilar (pCCA) & Distal (dCCA) \\
\hline Percent of CCA & $10-20 \%$ & $50-60 \%$ & $20-30 \%$ \\
\hline Location & Intrahepatic bile ducts & $\begin{array}{l}\text { Left, right common } \\
\text { hepatic ducts }\end{array}$ & Common bile duct \\
\hline Growth pattern & $\begin{array}{l}\text { Mass forming or peri-ductal infiltrating or } \\
\text { intraductal growth }\end{array}$ & \multicolumn{2}{|c|}{ Peri-ductal infiltrating or intraductal growth } \\
\hline Risk factors & \multicolumn{3}{|c|}{$\begin{array}{l}\text { Risk factors seen more commonly in eCCA: } \\
\text { - Choledocholithiasis } \\
\text { - Chronic Pancreatitis } \\
\text { - Primary Sclerosis Cholangitis } \\
\text { Risk factors seen more commonly in iCCA: } \\
\text { - Cirrhosis } \\
\text { - Viral Hepatitis (HBV, HCV) } \\
\text { - Liver Flukes (Opisthorchis viverrini, Clonorchis sinensis) } \\
\text { - Alcohol consumption } \\
\text { - Asbestos } \\
\text { General Risk factors: } \\
\text { - Diabetes Mellitus type } 2 \\
\text { - Obesity } \\
\text { - Cigarettes smoking }\end{array}$} \\
\hline Presentation & $\begin{array}{l}\text { Weight loss, abdominal pain, nonspecific } \\
\text { symptoms }\end{array}$ & \multicolumn{2}{|c|}{$\begin{array}{l}\text { Biliary obstruction, jaundice, abdominal pain, } \\
\text { weight loss }\end{array}$} \\
\hline \multirow[t]{2}{*}{$\begin{array}{l}\text { Detectable genetic abnormalities }(*=\text { FDA- } \\
\text { approved targeted therapy) }\end{array}$} & $\begin{array}{l}\text { FGFR Alterations (I0-20\%)* } \\
\text { IDHI Mutations (I5-20\%)* }\end{array}$ & \multicolumn{2}{|c|}{$\begin{array}{l}\text { KRAS mutations }(30-45 \%) \\
\text { ERBB2 (HER2) and ERBB3 alterations (10-15\%) }\end{array}$} \\
\hline & \multicolumn{3}{|c|}{$\begin{array}{l}\text { BRAF alterations (3-5\%) } \\
\text { Homologous Recombination Deficiency - DNA Repair Genes (ATM, BRCA, PLAB2, BAPI, ARIDIA, } \\
\text { etc) }(5-15 \%) \\
\text { MSI-high/dMMR }(2-5 \%)^{*}\end{array}$} \\
\hline
\end{tabular}

Alpha-fetoprotein (AFP) testing may be helpful to distinguish iCCA from hepatocellular carcinoma (HCC) in patients with chronic liver disease. Serum IgG4 testing should be considered in patients with possible eCCA to evaluate for IgG4-related cholangiopathy. ${ }^{24}$

For patients presenting with these symptoms or imaging findings concerning for CCA, multiphasic contrastenhanced computed tomography (CT) or magnetic resonance imaging (MRI) of the abdomen and pelvis is indicated for diagnosis, staging, and assessment of resectability. ${ }^{25} \mathrm{CT}$ imaging of the chest is also recommended to complete staging. Positron emission tomography (PET) is not routinely used, as it has limited sensitivity in detecting small, non-metastatic tumors as compared to CT and MRI; however, there is some evidence that it may be most useful for assessing lymph node and major vessel involvement, distant metastases, and recurrent disease in cases where $\mathrm{CT}$ and/or MRI are equivocal. $^{26}$

In addition to CT and MRI imaging, magnetic resonance cholangio-pancreatography (MRCP) allows for noninvasive evaluation of the biliary tree, tumor spread, and local invasion; however, it can be difficult at times to differentiate between benign and malignant strictures. ${ }^{27}$ In such cases and with more distal lesions, endoscopic retrograde cholangiopancreatography (ERCP) can be used for tissue sampling via brush cytology and biopsies, and to alleviate an obstruction if therapeutic intervention is necessary. ${ }^{24,28}$ When ERCP is unsuccessful or does not sufficiently visualize the biliary tree, percutaneous hepatic 
cholangiography (PTC) can be performed to sample more proximal and perihilar lesions. ${ }^{25}$ Endoscopic ultrasound (EUS) is useful in localizing strictures and allows for more accurate fine needle aspiration (FNA), including regional lymph node sampling; however, it is still limited by sampling error and limited ability to visualize proximal extrahepatic or peripheral lesions. For that reason, EUS is frequently combined with ERCP; together, EUS-ERCP has increased accuracy for diagnosis than either alone. ${ }^{25,29,30}$ Peroral cholangioscopy (POCS), which is performed during ERCP, can also be useful for establishing a diagnosis in indeterminate strictures. It is a safe adjunctive diagnostic technique that allows for direct visualization of the biliary tract and has a higher diagnostic yield than biopsies with ERCP alone. ${ }^{31,32}$

Notably, brush cytology has a high specificity but is limited by low sensitivity, particularly in patients with significant strictures, such as patients with PSC. Fluorescence in situ hybridization (FISH) analysis is now routinely used as part of the diagnostic evaluation as it significantly increases the sensitivity of cytology. ${ }^{33-37}$ Biopsy is usually not necessary for patients with localized disease undergoing resection. Patients with non-metastatic disease must be evaluated for resection or liver transplant prior to biopsy or biliary drainage, especially those with pCCA, in whom trans-peritoneal biopsy can lead to tumor seeding and may preclude them from transplantation. ${ }^{38}$

Diagnosis of eCCA can be particularly challenging due to biliary strictures, difficulty identifying a lesion on crosssectional imaging, and potential complications with invasive procedures, including cholangitis and tumor seeding within the biliary tree. ${ }^{33,39}$ In general, the degree of biliary obstruction can often present a difficult clinical challenge, limiting the options for therapeutic intervention, as well as the use of chemotherapy and radiation.

\section{Staging}

Staging of CCA is necessary for determining the extent of local invasion and resectability, as well as nodal involvement and distant disease. In recent years, significant changes have been made to the staging criteria for CCA. The 7th edition of the American Joint Committee on Cancer (AJCC) Staging Manual included the first unique staging classifications for iCCA, which was previously staged as HCC. This edition also introduced separate staging systems for pCCA and dCCA, which were previously grouped together as eCCA. The most recent 8th edition, published in 2017, further expanded the tumor (T) category in iCCA staging to include more information on size and degree of local invasion. Several studies have subsequently demonstrated that this edition allows for better prognostic stratification. ${ }^{40-42}$ The 8 th edition also includes more detail about depth of tumor invasion for dCCA and lymph node involvement for pCCA. ${ }^{43}$

Prior to these AJCC staging editions, two independent staging systems were developed for pCCA. The modified Bismuth-Corlette staging system classifies pCCA into four patterns based on extent and location of hepatic duct involvement alone. It does not include other clinical or pathologic features such as vascular invasion, lymph node involvement, or metastatic disease. ${ }^{44}$ Unlike the AJCC and modified Bismuth-Corlette systems, the Blumgart staging system is used for preoperative staging and has been shown to predict resectability and likelihood of metastatic disease. ${ }^{45}$ Those tumors that are classified as unresectable are often treated initially with systemic chemotherapy similar to that used in the metastatic setting, with the option for localized treatment in the setting of response.

\section{Molecular}

Cholangiocarcinomas demonstrate significant molecular heterogeneity and up to $50 \%$ have detectable mutations, with available or emerging therapeutic targets. ${ }^{20}$ Studies have identified differences in the mutational profiles of iCCA and eCCA, with implications on therapeutic interventions and prognosis. For this reason, molecular testing is recommended at the time of diagnosis of these tumors in order to inform therapeutic approach. ${ }^{46}$ Significant variability is found with regard to mutation frequencies described in the literature, which reflects differences in patients' gender, ethnicity, geography, and risk factors, as well as different identification methods and tumor classification between studies. ${ }^{1}$

In recent years, iCCA has been identified as a complex group of tumors that carry unique molecular abnormalities, some of which have new therapeutic implications. Specifically, mutations, fusions, and alterations in $I D H 1$, IDH2, FGFR1, FGFR2, FGFR3, Eph receptor 2 (EPHA2), $B A P 1$, and $M E T$ genes are found more commonly in iCCA. ${ }^{46}$ In perihilar and distal tumors, genetic alterations in $E R B B 2$, $A R I D 1 B, E L F 3, P B R M 1$, cAMP Dependent Protein Kinase (PRKACA, PRKACB) are more prevalent. ${ }^{47,48}$ Mutations in $K R A S, B R A F, P I K 3 C A$, and $C D K N 2 A / B$ are found with nearly equivalent frequency in both intrahepatic and extrahepatic subtypes. ${ }^{20,49}$ 
Approximately $13 \%$ of iCCA carry an Isocitrate Dehydrogenase $(I D H 1, I D H 2)$ mutation, which is associated with a poor prognosis. More than $65 \%$ of these mutations are seen in women and are almost never found in eCCA $(<1 \%) .{ }^{50}$ Activating Fibroblast Growth Factor Receptors -2 (FGFR2) fusions occur in about $20 \%$ of iCCA and may be associated with a favorable prognosis. Mutations in Chromatin Remodeling Genes BAPl and $B R A F$ are also more common in iCCA. ${ }^{8,19,29}$ On the other end, $E R B B 2$ overexpression is more common in eCCA and gallbladder cancer, occurring in $15-20 \%$ of cases. Mutations in KRAS and TP53 have also been identified more commonly in eCCA, but can also be found in iCCA, especially those derived from large bile ducts. ${ }^{8,20,29}$ NTRK fusions are found in $<1 \%$ of patients with biliary tract cancer, but when identified carry significant therapeutic implication.

The National Comprehensive Cancer Network (NCCN) guidelines recommend molecular testing as well as testing for microsatellite instability (MSI) or mismatch repair (MMR) as part of the diagnostic workup for both iCCA and eCCA. ${ }^{51}$ Microsatellite instability (MSI - high) or mismatch repair deficiency (dMMR) is found in $2-3 \%$ of biliary tract cancers. ${ }^{29}$ The finding of dMMR CCA has therapeutic implications regarding the use of immunotherapy. In addition, these patients, as well as those with a family history suggestive of BRCA1/2 mutation carriers, should be referred to a genetic counselor and considered for germline testing. Notably, $1-7 \%$ of all biliary tract cancers harbor a germline or somatic BRCA mutation. ${ }^{19,52}$ Tumor Mutational Burden (TMB) has also been identified as a predictor for response to immunotherapy and thus, should be routinely tested in these cases. ${ }^{53}$

Recently, the European Society of Medical Oncology (ESMO) Precision Medicine Working Group issued recommendations for the use of multi-gene next-generation sequencing (NGS) in patients with metastatic cancers, including CCA. ${ }^{54}$ In CCA, they recommend testing for mutations considered to be level I, which are actionable mutations with a validated targeted therapy, stating that larger panels are unlikely to be cost-effective. The level I mutations according to this group are IDH1, FGFR2, and NTRK. As noted, the NCCN guidelines recommend molecular testing in patients with unresectable or metastatic CCA but does not specify which mutations should be tested for or which platforms are appropriate. ${ }^{51}$ Some advocate for testing in early-stage CCA as well, as this may guide future treatment considering the very high rate of recurrent disease following resection. ${ }^{55}$ Based on the current data, we would recommend using comprehensive NGS molecular profiling that includes testing for $I D H 1$, FGFR2, NTRK, TMB, MSI/MMR, KRAS, TP53, BRCA 1/ 2, BRAF, CDKN2A/B, BAP1, PIK3CA, and HER2. Notably, there are data demonstrating a high failure rate of tissue biopsies in patients with CCA, with over $26 \%$ of samples inadequate for molecular profiling. ${ }^{56}$

\section{Prognosis}

Surgical resection remains the only potentially curative treatment for CCA; however, $70 \%$ of patients present with advanced stage disease and only $25 \%$ of patients with localized disease are candidates for resection. ${ }^{20}$ The 5 -year overall survival (OS) in patients following resection is $25-35 \%$ due to high relapse rates $(68-86 \%) .{ }^{19}$ For patients with advanced, unresectable disease, the median OS is 11.7 months $^{20}$ and poor performance status (ECOG $\geq 2$ ) is the strongest prognostic factor. ${ }^{57}$

\section{Treatment of Advanced Cholangiocarcinoma}

For patients with unresectable or metastatic CCA, systemic therapy is offered with palliative intent. The landscape of therapeutic options has been rapidly evolving over the past decade with the advent of novel targeted therapies. While combination chemotherapy remains the standard frontline option for such patients, an improved understanding of the molecular characteristics of CCA has allowed for the identification of therapeutic targets.

\section{Systemic Therapy}

CCA has been associated with a poor overall prognosis which can be marginally improved with standard cytotoxic chemotherapy (Table 2). Prior phase 2 trials have demonstrated response rates of 10-34\% with 5-fluorouracil (5$\mathrm{FU})$, and $17-36 \%$ with single-agent gemcitabine. $^{58}$ Several combination regimens have been investigated and have shown response rates of $19-24 \%$ with $5-\mathrm{FU} /$ platinum therapy, $25 \%$ with gemcitabine/capecitabine combination, $50 \%$ with gemcitabine/oxaliplatin, and $30 \%$ with gemcitabine/nab-paclitaxel regimens. ${ }^{58,59}$

The landmark ABC-02 phase 2 trial published in 2010 established the combination of gemcitabine with cisplatin as the standard frontline therapy for advanced CCA. In this study of 410 patients with locally advanced/metastatic hepatobiliary tumors, patients in the combination therapy arm achieved an 
Table 2 List of Completed and Ongoing Clinical Trial Evaluating Selected Targeted Agents in CCA

\begin{tabular}{|c|c|c|c|}
\hline Target & Agents & Available Data from Completed Trials & Ongoing \\
\hline \multirow{5}{*}{$\begin{array}{l}\text { FGFR } \\
\text { (FGFR-2 } \\
\text { fusion/re- } \\
\text { arrangement) }\end{array}$} & Pemigatinib* & $\begin{array}{l}\text { Phase } 2 \text { FIGHT } 202 \text { trial: } \\
\text { ORR }-35.5 \% \\
\text { mOS }-21.1 \text { mos }\end{array}$ & $\begin{array}{l}\text { FIGHT-302 - [NCT03656536] } \\
\text { Phase } 3 \text { - front line vs gemcitabine + cisplatin }\end{array}$ \\
\hline & $\begin{array}{l}\text { Futibatinib (TAS- } \\
\text { I20) }\end{array}$ & $\begin{array}{l}\text { Phase } 2 \text { trial FOENIX-CCA2: } \\
\text { ORR }-37.7 \% \\
\text { DCR }-82 \% \\
\text { mPFS }-7.2 \text { mos }\end{array}$ & $\begin{array}{l}\text { FOENIX-CCA3 - [NCT04093362] } \\
\text { Phase } 3 \text { - front line vs gemcitabine + cisplatin }\end{array}$ \\
\hline & $\begin{array}{l}\text { Infigratinib* } \\
\text { (BGJ398) }\end{array}$ & $\begin{array}{l}\text { Phase } 2 \text { trial: } \\
\text { ORR }-23.1 \% \% \\
\text { mPFS }-7.3 \mathrm{mos} \\
\text { mOS }-12.2 \mathrm{~m}\end{array}$ & $\begin{array}{l}\text { PROOF trial - [NCT03773302] } \\
\text { Phase } 3 \text { - front line vs gemcitabine + cisplatin }\end{array}$ \\
\hline & $\begin{array}{l}\text { Derazantinib } \\
\left(^{(A R Q 087}\right)^{108}\end{array}$ & $\begin{array}{l}\text { Phase I/2: } \\
\text { ORR - } 20.7 \% \\
\text { DCR - } 82.8 \% \\
\text { mPFS - } 5.7 m\end{array}$ & $\begin{array}{l}\text { FIDES-0I- [NCT032303 I8] } \\
\text { Phase } 2 \text { - 2nd line therapy }\end{array}$ \\
\hline & ICP-I92 & $\mathrm{N} / \mathrm{A}$ & $\begin{array}{l}\text { Phase I evaluating single agent activity in advanced } \\
\text { CCA and other solid tumors [NCT04565275] }\end{array}$ \\
\hline \multirow[t]{7}{*}{ IDH } & $\begin{array}{l}\text { Ivosidenib* (AG- } \\
\text { I20) }\end{array}$ & $\begin{array}{l}\text { ClarIDHy phase } 3 \text { study vs placebo: } \\
\text { mPFS }-6.9 \mathrm{~m} \text { vs } 1.4 \mathrm{~m} \\
\mathrm{mOS}-10.8 \mathrm{~m} \text { vs } 9.7 \mathrm{~m}\end{array}$ & $\begin{array}{l}\text { Phase I front line in combination with gemcitabine } \\
\text { and cisplatin [NCT04088/88] }\end{array}$ \\
\hline & $\begin{array}{l}\text { Enasidenib (AG- } \\
221 \text { ) }\end{array}$ & $\mathrm{N} / \mathrm{A}$ & $\begin{array}{l}\text { Phase I results evaluating single agent activity in } \\
\text { advanced CCA and other solid tumors with IDH2 } \\
\text { mutations [NCT02273739] }\end{array}$ \\
\hline & Olaparib & $\mathrm{N} / \mathrm{A}$ & $\begin{array}{l}\text { Phase } 2 \text { evaluating single agent activity in IDHI and } \\
I D H 2 \text { mutated CCA [NCT032I2274] }\end{array}$ \\
\hline & $\begin{array}{l}\text { Olaparib + } \\
\text { ceralasertib AZD } \\
6738 \text { (ATR } \\
\text { inhibitor) }\end{array}$ & $\mathrm{N} / \mathrm{A}$ & $\begin{array}{l}\text { Phase } 2 \text { evaluating the combination in IDHI and } \\
\text { IDH2 mutated CCA [NCT03878095] }\end{array}$ \\
\hline & $\begin{array}{l}\text { Olaparib } \\
\text { +Durvalumab }\end{array}$ & N/A & $\begin{array}{l}\text { Phase } 2 \text { evaluating the combination in IDHI and } \\
\text { IDH2 mutated CCA [NCT0399|832] }\end{array}$ \\
\hline & LY34I 0738 & N/A & $\begin{array}{l}\text { Phase I evaluating single agent in IDH mutated CCA } \\
\text { and other solid tumors [NCT0452I } 686 \text { ] }\end{array}$ \\
\hline & $\begin{array}{l}\text { Olutasidenib (FT- } \\
2102)\end{array}$ & N/A & $\begin{array}{l}\text { Phase } \mathrm{I} / 2 \text { evaluating single agent activity in advanced } \\
\mathrm{CCA} \text { and other solid tumors with IDHI mutations } \\
\text { [NCT036848I I] }\end{array}$ \\
\hline \multirow[t]{2}{*}{$\begin{array}{l}\text { DNA Repair } \\
\text { Gene } \\
\text { mutations }\end{array}$} & Olaparib & $\mathrm{N} / \mathrm{A}$ & $\begin{array}{l}\text { Phase } 2 \text { evaluating single agent activity in advanced } \\
\text { CCA with aberrant DNA repair gene mutations (i.e: } \\
\text { BRCA, PALB2, ATM, ATR, etc.) [NCT0404283I] }\end{array}$ \\
\hline & Niraparib & $\mathrm{N} / \mathrm{A}$ & $\begin{array}{l}\text { Phase } 2 \text { evaluating single agent activity in advanced } \\
\text { CCA and other solid tumors with aberrant DNA } \\
\text { repair gene mutations in BAPI and other genes (i.e: } \\
\text { PALB2, ATM, ATR, etc.) [NCT03207347] }\end{array}$ \\
\hline
\end{tabular}

(Continued) 
Table 2 (Continued).

\begin{tabular}{|c|c|c|c|}
\hline Target & Agents & Available Data from Completed Trials & Ongoing \\
\hline \multirow[t]{7}{*}{ HER2 } & Varlitinib $^{109}$ & $\begin{array}{l}\text { Randomized Phase } 2 \text { TREETOPP study } \\
\text { [NCT03093870] } \\
\text { - Capecitabine } \pm \text { Varlitinib: } \\
\text { ORR } 9.4 \% \text { vs } 4.8 \% \\
\text { No difference in mPFS or mOS }\end{array}$ & $\mathrm{N} / \mathrm{A}$ \\
\hline & $\begin{array}{l}\text { Trastuzumab + } \\
\text { Pertuzumab }\end{array}$ & $\begin{array}{l}\text { Phase } 2 \text { study of multiple HER2 overexpressing or } \\
\text { amplified tumors. Data from small cohort of } \\
\text { advanced CCA patients - ORR- } 37.5 \% \text { for HER2 } \\
\text { over expression. [NCT0209II4I] }\end{array}$ & $\mathrm{N} / \mathrm{A}$ \\
\hline & $\begin{array}{l}\text { Trastuzumab + } \\
\text { Tucatinib }\end{array}$ & $\mathrm{N} / \mathrm{A}$ & $\begin{array}{l}\text { Basket study evaluating the combination in advanced } \\
\text { CCA and other solid tumors harboring HER2 } \\
\text { alterations [NCT04579380] }\end{array}$ \\
\hline & $\begin{array}{l}\text { Trastuzumab + } \\
\text { Tucatinib }+ \\
\text { FOLFOX }\end{array}$ & $\mathrm{N} / \mathrm{A}$ & $\begin{array}{l}\text { Phase I/2 evaluating the combination in HER2 } \\
\text { positive advanced CCA and other GI cancers } \\
\text { [NCT04430738] }\end{array}$ \\
\hline & Lapatanib 110 & $\begin{array}{l}\text { Open label phase } 2 \text { closed early due to futility. No } \\
\text { responses seen. }\end{array}$ & $\mathrm{N} / \mathrm{A}$ \\
\hline & $\begin{array}{l}\text { Zanidatamab } \\
\text { (ZW25) }\end{array}$ & $\mathrm{N} / \mathrm{A}$ & $\begin{array}{l}\text { Phase } 2 \text { study evaluating single agent activity in HER2 } \\
\text { positive advanced CCA [NCT0446689I] }\end{array}$ \\
\hline & $\begin{array}{l}\text { Trastuzumab } \\
\text { deruxtecan }\end{array}$ & $\mathrm{N} / \mathrm{A}$ & $\begin{array}{l}\text { Phase } 2 \text { study evaluating single agent activity in HER2 } \\
\text { positive advanced CCA and other solid tumors. } \\
\text { [NCT04482309] }\end{array}$ \\
\hline $\begin{array}{l}\text { BRAF V600E } \\
\text { mutation }\end{array}$ & $\begin{array}{l}\text { Dabrafenib + } \\
\text { Trametinib }\end{array}$ & $\begin{array}{l}\text { Phase } 2 \text { (ROAR) basket trial showing } 5 \text { I\% ORR in } \\
\text { advanced CCA patients. [NCT02034II0] }\end{array}$ & $\mathrm{N} / \mathrm{A}$ \\
\hline PI3K & Copanlisib"1' & $\begin{array}{l}\text { Phase } 2 \text { study in combination with gemcitabine and } \\
\text { cisplatin in Ist line did not meet the primary end } \\
\text { point of improved } 6 \mathrm{~m} \text { PFS [NCT0263/590] }\end{array}$ & $\mathrm{N} / \mathrm{A}$ \\
\hline
\end{tabular}

Note: *FDA-approved targeted therapy.

Abbreviations: ORR, objective response rate; mPFS, median progression free survival; mOS, median overall survival; ATR, ataxia telangiectasia and RAD3 related (ATR) kinase.

OS advantage of 3.6 months as compared to treatment with single-agent gemcitabine (median OS 11.7 months in the combination arm vs 8.1 months in the gemcitabine arm). ${ }^{60}$ With regard to response rates, $81.4 \%$ of patients in the combination arm had a complete/partial response or stable disease, while $71.8 \%$ of patients who received single-agent gemcitabine achieved such outcomes. ${ }^{60,61}$ A phase 2 trial of 60 patients investigating the efficacy of the addition of nab-paclitaxel to gemcitabine/cisplatin demonstrated a similar disease control rate of $84 \%$ with an improved median OS of 19.2 months. ${ }^{62}$ Based on this data, a phase 3 trial is ongoing using this triplet combination in the frontline setting [NCT03768414]. Similarly, a phase 3 study comparing a combination of gemcitabine, cisplatin, and an oral fluoropyrimidine (S1) to the gemcitabine/cisplatin backbone showed a small but statistically significant improvement in median OS (13.6 months with the triplet therapy vs 12.6 months with gemcitabine/cisplatin). ${ }^{63}$ A recent report from the AMEBICA PRODIGE 38 study did not show any benefit with the use of 5-FU/irinotecan/oxaliplatin (FOLFIRINOX) over gemcitabine/cisplatin in the front-line setting (median OS 11.7 months vs 14.3 months, respectively, [95\% confidence interval (CI) 11.3-16.5]). ${ }^{64}$

After progression on frontline gemcitabine/cisplatin therapy, 5-FU-based systemic regimens remain the current standard of care, though targeted therapies are evolving in this space as discussed below. The phase $3 \mathrm{ABC}-06$ trial studying the efficacy of second-line therapy with 5-FU/oxaliplatin 
(FOLFOX) showed that active symptom control in addition to FOLFOX improved OS when compared to active symptom control alone (median OS 6.2 months in the combination arm vs 5.3 months in the active symptom control arm). ${ }^{65}$ There are limited data for the use of 5-FU with irinotecan (FOLFIRI) in the second-line setting. A small retrospective study including 12 patients treated with this regimen showed a median OS of 5 months. ${ }^{49}$ Recently, Yoo et al presented the results of the Korean NIFTY study which randomized patients to 5-FU/ Leucovorin with or without liposomal irinotecan after progression on gemcitabine/cisplatin. The study demonstrated improvement in progression-free survival (PFS) and OS with the addition of liposomal irinotecan (PFS 7.1 months vs 1.4 months, HR 0.56, $\mathrm{p}=0.0019$; OS 8.6 months vs 5.5 months, HR 0.68, $\mathrm{p}=0.034){ }^{66}$

\section{Role of Radiation Therapy and Liver Directed Therapy}

At present, radiation is only used for palliative purposes for patients with unresectable or metastatic CCA for treatment of painful metastatic sites or in attempt to achieve local control for locally advanced tumors. Patients with liver predominant disease who have partial response or stable disease following 6 months of chemotherapy may be considered for liver directed therapy with trans-arterial radioembolization (TARE) or yttrium-90 (Y-90), although prospective data supporting this approach are limited. ${ }^{67}$ One systematic review of Y-90 treatment for iCCA reported a median OS of 15.5 months with $28 \%$ of patients having partial radiographic response and $54 \%$ with stable disease ${ }^{68}$ The use of external beam radiation or stereotactic radiation (SBRT) for iCCA has been sparsely evaluated. A study by Hong et al reported a 2-year OS rate of $46.5 \%$ in 37 patients with iCCA who received high-dose hypofractionated proton therapy. ${ }^{69}$ The ongoing ABC-07 study is a multicenter clinical trial evaluating the addition of SBRT to 6 cycles of gemcitabine/ cisplatin versus 8 cycles of chemotherapy only for localized unresectable CCA. The use of hepatic arterial infusion of chemotherapy was also tested in the setting of unresectable localized iCCA in a small phase 2 trial, showing $84 \%$ of patients having disease control at 6 months, with a median OS of 25 months. $^{70}$

\section{Immunotherapy}

The use of immunotherapy with checkpoint inhibitors has been tested in advanced CCA with disappointing results. The phase 2 KEYNOTE-158 trial which studied the efficacy and safety of pembrolizumab (an anti-PD-L1 monoclonal antibody) in refractory solid tumors included 104 patients with biliary tract primary tumors. The study found an overall response rate of $5.8 \%$ and a median OS of 9.1 months in these patients. Response rates were slightly higher for patients with PD-L1 combined positive score (CPS) $\geq 1$; these patients had an overall response rate of $6.6 \%$. However, this did not translate into improved overall survival advantage. ${ }^{71}$

Currently, immunotherapy is only approved for CCA patients with dMMR tumors based on a study evaluating the efficacy of pembrolizumab in dMMR tumors. The study was comprised of patients with 12 different tumor types including CCA and reported a 53\% objective response rate with $21 \%$ of patients achieving a complete response. ${ }^{72}$ This study led to the site agnostic approval of pembrolizumab for dMMR tumors. Similarly, CCA tumors with high TMB would be candidates for immunotherapy based on a similar agnostic approval. ${ }^{72}$ Ongoing trials are attempting to establish the role of immunotherapy in combination with chemotherapy in this disease such as ABC-09 study [NCT03260712] evaluating the combination of pembrolizumab with gemcitabine/cisplatin. ${ }^{73}$ Similarly, the TOPAZ-1 study is a phase 3 trial testing the combination of gemcitabine/cisplatin with or without durvalumab, an anti-PD-L1 monoclonal antibody [NCT03875235]. ${ }^{74}$

\section{Targeted Therapy}

The advent of tumor genomic sequencing and the development of targeted therapeutics directed at mutations at the molecular level has greatly expanded the therapeutic arsenal for biliary tract tumors. ${ }^{47}$ In fact, there are data to suggest that as many as $38.9 \%$ of patients with biliary tract cancers may harbor a potentially targetable mutation. ${ }^{75}$ Other studies have shown that $11-15 \%$ of patients with biliary tract cancers have mutations in cancer risk genes, and experts have suggested that routine germline genetic testing may therefore be advantageous from a clinical standpoint in the care of these patients. ${ }^{76}$

Several trials have been completed investigating the role of targeted therapies after progression on standard chemotherapy. Notable trials that have led to FDA approval of targeted agents include the ClarIDHy and FIGHT-202 trials targeting $I D H 1$ and $F G F R 2$, respectively. ${ }^{77,78}$ The phase 3 ClarIDHy trial investigating the use of ivosidenib in patients with IDH1-mutated CCA who had previously progressed on up to 2 prior chemotherapeutic regimens found that patients 
derived a substantial PFS benefit of 6.9 months as opposed to 1.4 months in the placebo arm (HR 0.37, 95\% CI 0.25-0.54, $\mathrm{p}<0.0001)$. Median OS was 10.8 months for ivosidenib versus 9.7 months for placebo (HR 0.69, 95\% CI 0.44 1.10), which was not statistically significant due to cross over of patients in the control arm. ${ }^{77}$ Additional agents are under development in this space including IDH305 (NCT02381886), FT-2012 (Olutasidenib) (NCT03684811), BAY-1436032 (NCT02746081), and LY3410738 (NCT04 521686). ${ }^{79,80}$ These newer agents may offer treatment options for patients who have progressed on treatment with ivosidenib.

One of the most studied targets in CCA is FGFR, with multiple agents under evaluation for management of patients with FGFR2 fusion/rearrangement (Table 2). The phase 2 FIGHT-202 trial of the selective FGFR1-3 inhibitor, pemigatinib, in patients with advanced CCA enrolled 3 cohorts of 107 patients with FGFR2 fusions or rearrangements, 20 patients with other $F G F / F G F R$ alterations, and 18 patients with no $F G F / F G F R$ alterations who have progressed on at least one line of therapy. Patients with FGFR2 fusions/rearrangements demonstrated a $35.5 \%$ objective response rate (ORR), while no responses were seen in the other cohorts. Within this group, a PFS of 6.9 months was seen and median OS was noted to be 21.1 months. ${ }^{78}$ Pemigatinib is now approved by the FDA for the treatment of patients with advanced iCCA with FGFR2 fusion in the second-line setting. Recently, data from the FOENIX-CCA2 phase 2 study testing the FGFR inhibitor, futibatinib, in patients with advanced CCA. The study enrolled 103 patients with iCCA harboring FGFR2 fusions/rearrangements that progressed on at least one prior line of therapy and reported an ORR of $37.7 \%$, disease control rate of $82 \%$, and median PFS of 7.2 months. ${ }^{81}$ Based on these data, the FDA granted breakthrough therapy designation to this agent that is now added to the treatment arsenal. Infigratinib (BGJ398) is another FGFR inhibitor that is currently in clinical trials. ${ }^{82}$ The results of the phase 2 trial with infigratinib with 108 patients with FGFR2 fusions/rearrangements were recently presented, demonstrating an ORR of $23.1 \%$, median PFS of 7.3 months, and median OS of 12.2 months. ${ }^{83}$ Based on these results, infigratinib has been recently approved for use in the second-line setting.

Initial reports are now emerging of an acquired resistance to these inhibitors, often associated with secondary FGFR2 kinase domain mutations. Goyal et al reported four cases of patients who responded to futibatinib following progression on other FGFR inhibitors. ${ }^{84}$ These reports suggest the potential benefit of sequencing these agents and evaluation of acquired mutations using circulating tumor DNA (ctDNA) at the time of disease progression. These agents are now being tested in large randomized clinical trials in the front-line setting in comparison to standard chemotherapy - FIGHT-302 trial (pemigatinib) [NCT03656536], PROOF trial (infigratinib) [NCT03773302], FOENIX-CCA3 trial (futibatinib) [NCT04093362]. Multiple additional agents are under development at various stages for tumors harboring an FGFR alteration (Table 2) offering the promise of multiple treatment options for these patients.

Like FGFR and IDH, NTRK fusion-directed therapy is also considered standard of care for eligible patients. Three separate phase 1 or 2 trials investigating the use of entrectinib in patients with advanced or metastatic cancer with NTRK fusions across 19 tumor types showed a cumulative $57 \%$ response rate with $7 \%$ of patients achieving a complete response. ${ }^{85}$ Larotrectinib was evaluated in a phase $1 / 2$ study of patients with malignancies harboring $T R K$-fusion and showed a $75-80 \%$ response rate. ${ }^{86}$ Although the rate of these mutations is low in CCA tumors, the significant clinical benefit for those patients with tumors harboring this alteration is significant and supports the wide testing of all patients for this molecular marker.

Several studies investigated other molecular targets and pathways central to the pathogenesis of CCA. For example, EGFR- and VEGF-directed therapies have shown limited efficacy in this setting thus far, although importantly, these studies were performed in patients regardless of mutational status. ${ }^{87-101}$ HER2/neu genomic alterations (overexpression or mutations) are also found in some CCAs, more commonly in eCCA, and have shown some response to HER2 blockade with trastuzumab plus pertuzumab or neratinib in early small clinical trials. ${ }^{102,103}$ An ongoing phase 2 study of Trastuzumab Deruxtecan (DS8201) will evaluate the efficacy of this agent in HER2 positive biliary tract cancers. ${ }^{104}$

Overexpression of the proto-oncogene MET has been found in $34 \%$ of biliary tract cancers, and a small phase 1 trial evaluating the efficacy of a MET inhibitor in combination with gemcitabine reported that $46 \%$ of patients had stable disease and $20 \%$ achieved a partial response. ${ }^{19}$ Treatment with the dabrafenib (BRAF inhibitor) and trametinib (MEK inhibitor) has been evaluated for patients with $B R A F$ V600E mutated CCA as part of the ROAR basket study showing an ORR of $51 \%$ in this 
population. ${ }^{105}$ Cabozantinib, which inhibits both VEGFR2 and MET, demonstrated significant toxicity with limited clinical benefit. ${ }^{106}$ Other tyrosine kinase inhibitors including vandetanib, sorafenib, sunitinib, cediranib, and selumetinib have been studied either alone or in combination with other agents with variable efficacy. ${ }^{19}$

While the aforementioned therapies targeting IDHI, FGFR2, and NTRK remain the only interventions currently approved for use, many other targeted therapies have been investigated or are currently under investigation for use in this disease. Table 2 outlines the prominent completed and ongoing trials in this area. Given the heterogeneity of this disease, we should expect to see an evolution in its care, with classification of tumors based on their molecular subtype, and utilizing this to personalize therapy.

\section{Future Directions}

Cholangiocarcinomas are highly heterogeneous clinically and molecularly and thus additional research is warranted in order to better define the optimal treatment approach for each subtype. Considering close to $50 \%$ of these tumors harbor some identifiable mutation, molecular profiling is recommended for all patients to help guide treatment decisions. While research continues in this disease, we will see additional trials evaluating combination treatments for known targets, as well as new modalities towards novel targets. Furthermore, as we start to use these targeted therapies more widely, resistant mechanisms will emerge and studies guiding us on how to sequence these drugs will be of high importance. In addition, studies are also evaluating new chemotherapy agents and combinations for this cancer such as acelarin (NUC-1031, a first-in-class nucleotide ana$\log$ with greater intracellular concentration), which is being studied with cisplatin in the phase 1 ABC-08 study and in a phase 3 trial compared to gemcitabine/cisplatin [NCT04163900]. ${ }^{107}$ There are also ongoing trials investigating the efficacy and tolerability of nanoliposomal irinotecan (Onivyde) with 5-FU as compared to gemcitabine/cisplatin in the front-line setting [NCT03044587] and trifluridine/ tipiracil hydrochloride for previously treated advanced CCA [NCT04076761]. The active and vibrant research in this disease allows for increased hope for improved outcomes in patients diagnosed with this aggressive cancer.

\section{Disclosure}

Dr Efrat Dotan reports grants and/or personal fees from Pfizer, Lilly, Incyte, AstraZeneca, MedImmune, Boston Biomedical (SDP), QED, and Basilea, outside the submitted work. The authors report no other conflicts of interest in this work.

\section{References}

1. Kendall T, Verheij J, Gaudio E, et al. Anatomical, histomorphological and molecular classification of cholangiocarcinoma. Liver Int. 2019;39(Suppl 1):7-18. doi:10.1111/liv.14093.

2. Siegel RL, Miller KD, Jemal A. Cancer statistics, 2020. $C A$ Cancer J Clin. 2020;70(1):7-30. doi:10.3322/caac.21590.

3. Ben-Menachem T. Risk factors for cholangiocarcinoma. Eur $J$ Gastroenterol Hepatol. 2007;19(8):615-617. doi:10.1097/MEG. 0b013e328224b935.

4. Chapman RW. Risk factors for biliary tract carcinogenesis. Ann Oncol. 1999;10(Suppl 4):308-311. doi:10.1093/annonc/10. suppl_4.S308

5. Clements O, Eliahoo J, Kim JU, Taylor-Robinson SD, Khan SA. Risk factors for intrahepatic and extrahepatic cholangiocarcinoma: a systematic review and meta-analysis. $J$ Hepatol. 2020;72(1):95-103. doi:10.1016/j.jhep.2019.09.007.

6. Tyson GL, El-Serag HB. Risk factors for cholangiocarcinoma. Hepatology. 2011;54(1):173-184. doi:10.1002/hep.24351.

7. Khan SA, Toledano MB, Taylor-Robinson SD. Epidemiology, risk factors, and pathogenesis of cholangiocarcinoma. $H P B$ (Oxford). 2008;10(2):77-82. doi:10.1080/13651820801992641.

8. Labib PL, Goodchild G, Pereira SP. Molecular pathogenesis of cholangiocarcinoma. BMC Cancer. 2019;19(1):185. doi:10.1186/ s12885-019-5391-0.

9. Squadroni M, Tondulli L, Gatta G, Mosconi S, Beretta G, Labianca R. Cholangiocarcinoma. Crit Rev Oncol Hematol. 2017;116:11-31. doi:10.1016/j.critrevonc.2016.11.012.

10. Mukkamalla SKR, Naseri HM, Kim BM, Katz SC, Armenio VA. Trends in incidence and factors affecting survival of patients with cholangiocarcinoma in the United States. J Natl Compr Canc Netw. 2018;16(4):370-376. doi:10.6004/jnccn.2017.7056.

11. Van Dyke AL, Shiels MS, Jones GS, et al. Biliary tract cancer incidence and trends in the United States by demographic group, 1999-2013. Cancer. 2019;125(9):1489-1498. doi:10.1002/cncr. 31942.

12. Saha SK, Zhu AX, Fuchs CS, Brooks GA. Forty-year trends in cholangiocarcinoma incidence in the U.S.: intrahepatic disease on the rise. Oncologist. 2016;21(5):594-599. doi:10.1634/theoncologist.2015-0446.

13. Khan SA, Taylor-Robinson SD, Toledano MB, Beck A, Elliott P, Thomas HC. Changing international trends in mortality rates for liver, biliary and pancreatic tumours. $J$ Hepatol. 2002;37(6):806813. doi:10.1016/s0168-8278(02)00297-0.

14. Nakanuma Y, Sato Y, Harada K, Sasaki M, Xu J, Ikeda H. Pathological classification of intrahepatic cholangiocarcinoma based on a new concept. World J Hepatol. 2010;2(12):419-427. doi:10.4254/wjh.v2.i12.419.

15. Miyazaki M, Ohtsuka M, Miyakawa S, et al. Classification of biliary tract cancers established by the Japanese Society of Hepato-Biliary-Pancreatic Surgery: 3rd English edition. $J$ Hepatobiliary Pancreat Sci. 2015;22(3):181-196. doi:10.1002/ jhbp. 211

16. Lim JH. Cholangiocarcinoma: morphologic classification according to growth pattern and imaging findings. AJR Am J Roentgenol. 2003;181(3):819-827. doi:10.2214/ajr.181.3.1810819

17. Banales JM, Cardinale V, Carpino G, et al. Expert consensus document: cholangiocarcinoma: current knowledge and future perspectives consensus statement from the European Network for the Study of Cholangiocarcinoma (ENS-CCA). Nat Rev Gastroenterol Hepatol. 2016;13(5):261-280. doi:10.1038/ nrgastro.2016.51 
18. Vijgen S, Terris B, Rubbia-Brandt L. Pathology of intrahepatic cholangiocarcinoma. Hepatobiliary Surg Nutr. 2017;6(1):22-34. doi:10.21037/hbsn.2016.11.04

19. Adeva J, Sangro B, Salati M, et al. Medical treatment for cholangiocarcinoma. Liver Int. 2019;39(Suppl 1):123-142. doi:10. 1111/liv. 14100

20. Banales JM, Marin JJG, Lamarca A, et al. Cholangiocarcinoma 2020: the next horizon in mechanisms and management. Nat Rev Gastroenterol Hepatol. 2020;17(9):557-588. doi:10.1038/s415 75-020-0310-z

21. Wang X, Yu GY, Chen M, Wei R, Chen J, Wang Z. Pattern of distant metastases in primary extrahepatic bile-duct cancer: a SEER-based study. Cancer Med. 2018;7(10):5006-5014. doi:10. 1002/cam4.1772

22. Yan X, Wang P, Zhu Z, et al. Site-specific metastases of intrahepatic cholangiocarcinoma and its impact on survival: a population-based study. Future Oncol. 2019;15(18):2125-2137. doi:10. 2217/fon-2018-0846

23. Tsen A, Barbara M, Rosenkranz L. Dilemma of elevated CA 19-9 in biliary pathology. Pancreatology. 2018;18(8):862-867. doi:10.1016/j.pan.2018.09.004

24. Forner A, Vidili G, Rengo M, Bujanda L, Ponz-Sarvise M, Lamarca A. Clinical presentation, diagnosis and staging of cholangiocarcinoma. Liver Int. 2019;39(Suppl 1):98-107. doi:10.11 11/liv.14086

25. Sainani NI, Catalano OA, Holalkere NS, Zhu AX, Hahn PF, Sahani DV. Cholangiocarcinoma: current and novel imaging techniques. Radiographics. 2008;28(5):1263-1287. doi:10.1148/rg.285075183.

26. Lamarca A, Barriuso J, Chander A, et al. 18F-fluorodeoxyglucose positron emission tomography ((18)FDG-PET) for patients with biliary tract cancer: systematic review and meta-analysis. $J$ Hepatol. 2019;71(1):115-129. doi:10.1016/j.jhep.2019.01.038.

27. Jhaveri KS, Hosseini-Nik H. MRI of cholangiocarcinoma. J Magn Reson Imaging. 2015;42(5):1165-1179. doi:10.1002/jmri.24810.

28. Brandi G, Venturi M, Pantaleo MA, Ercolani G. Cholangiocarcinoma: current opinion on clinical practice diagnostic and therapeutic algorithms: a review of the literature and a long-standing experience of a referral center. Dig Liver Dis. 2016;48(3):231-241. doi:10.1016/j.dld.2015.11.017

29. Valle JW, Kelley RK, Nervi B, Oh DY, Zhu AX. Biliary tract cancer. Lancet. 2021;397(10272):428-444. doi:10.1016/S0140-6736(21)00 153-7

30. Eloubeidi MA, Chen VK, Jhala NC, et al. Endoscopic ultrasoundguided fine needle aspiration biopsy of suspected cholangiocarcinoma. Clin Gastroenterol Hepatol. 2004;2(3):209-213. doi:10. 1016/s1542-3565(04)00005-9

31. Pereira P, Santos S, Morais R, et al. Role of peroral cholangioscopy for diagnosis and staging of biliary tumors. Dig Dis. 2020;38(5):431-440. doi:10.1159/000504910.

32. Korrapati P, Ciolino J, Wani S, et al. The efficacy of peroral cholangioscopy for difficult bile duct stones and indeterminate strictures: a systematic review and meta-analysis. Endosc Int Open. 2016;04(03):E263-E275. doi:10.1055/s-0042-100194

33. Rizvi S, Gores GJ. Current diagnostic and management options in perihilar cholangiocarcinoma. Digestion. 2014;89(3):216-224. doi:10.1159/000360791

34. Trikudanathan G, Navaneethan U, Njei B, Vargo JJ, Parsi MA. Diagnostic yield of bile duct brushings for cholangiocarcinoma in primary sclerosing cholangitis: a systematic review and metaanalysis. Gastrointest Endosc. 2014;79(5):783-789. doi:10.1016/ j.gie.2013.09.015

35. Navaneethan U, Njei B, Venkatesh PG, Vargo JJ, Parsi MA. Fluorescence in situ hybridization for diagnosis of cholangiocarcinoma in primary sclerosing cholangitis: a systematic review and meta-analysis. Gastrointest Endosc. 2014;79(6):943-950 e3. doi:10.1016/j.gie.2013.11.001
36. Ferrone CR, Ting DT, Shahid M, et al. The ability to diagnose intrahepatic cholangiocarcinoma definitively using novel branched DNA-enhanced albumin RNA in situ hybridization technology. Ann Surg Oncol. 2016;23(1):290-296. doi:10.1245/ s10434-014-4247-8.

37. Kamp E, Dinjens WNM, Doukas M, et al. Optimal tissue sampling during ERCP and emerging molecular techniques for the differentiation of benign and malignant biliary strictures. Therap Adv Gastroenterol. 2021;14:17562848211002023. doi:10.1177/ 17562848211002023.

38. Heimbach JK, Sanchez W, Rosen CB, Gores GJ. Trans-peritoneal fine needle aspiration biopsy of hilar cholangiocarcinoma is associated with disease dissemination. HPB (Oxford). 2011;13 (5):356-360. doi:10.1111/j.1477-2574.2011.00298.x.

39. Huguet JM, Lobo M, Labrador JM, et al. Diagnostic-therapeutic management of bile duct cancer. World J Clin Cases. 2019;7 (14):1732-1752. doi:10.12998/wjcc.v7.i14.1732

40. Lee AJ, Chun YS. Intrahepatic cholangiocarcinoma: the AJCC/ UICC 8th edition updates. Chin Clin Oncol. 2018;7(5):52. doi:10.21037/cco.2018.07.03

41. Spolverato G, Bagante F, Weiss M, et al. Comparative performances of the 7th and the 8th editions of the American Joint Committee on Cancer staging systems for intrahepatic cholangiocarcinoma. J Surg Oncol. 2017;115(6):696-703. doi:10.1002/ jso. 24569

42. Kang SH, Hwang S, Lee YJ, et al. Prognostic comparison of the 7th and 8th editions of the American Joint Committee on Cancer staging system for intrahepatic cholangiocarcinoma. J Hepatobiliary Pancreat Sci. 2018;25(4):240-248. doi:10.1002/jhbp.543

43. Amin MB, Greene FL, Edge SB, et al. The eighth edition AJCC cancer staging manual: continuing to build a bridge from a population-based to a more "personalized" approach to cancer staging. CA Cancer J Clin. 2017;67(2):93-99. doi:10.3322/caac.21388.

44. Bismuth $\mathrm{H}$, Nakache R, Diamond T. Management strategies in resection for hilar cholangiocarcinoma. Ann Surg. 1992;215 (1):31-38. doi:10.1097/00000658-199201000-00005.

45. Matsuo K, Rocha FG, Ito K, et al. The Blumgart preoperative staging system for hilar cholangiocarcinoma: analysis of resectability and outcomes in 380 patients. J Am Coll Surg. 2012;215 (3):343-355. doi:10.1016/j.jamcollsurg.2012.05.025.

46. Lowery MA, Ptashkin R, Jordan E, et al. Comprehensive molecular profiling of intrahepatic and extrahepatic cholangiocarcinomas: potential targets for intervention. Clin Cancer Res. 2018;24 (17):4154-4161. doi:10.1158/1078-0432.CCR-18-0078.

47. Goldstein D, Lemech C, Valle J. New molecular and immunotherapeutic approaches in biliary cancer. ESMO Open. 2017;2(Suppl 1):e000152. doi:10.1136/esmoopen-2016-000152.

48. Mahipal A, Tella SH, Kommalapati A, Anaya D, Kim R. FGFR2 genomic aberrations: achilles heel in the management of advanced cholangiocarcinoma. Cancer Treat Rev. 2019;78:1-7. doi:10.1016/j.ctrv.2019.06.003.

49. Caparica R, Lengele A, Bekolo W, Hendlisz A. FOLFIRI as second-line treatment of metastatic biliary tract cancer patients. Autops Case Rep. 2019;9(2):e2019087. doi:10.4322/acr.2019.087.

50. Boscoe AN, Rolland C, Kelley RK. Frequency and prognostic significance of isocitrate dehydrogenase 1 mutations in cholangiocarcinoma: a systematic literature review. $J$ Gastrointest Oncol. 2019;10(4):751-765. doi:10.21037/jgo.2019.03.10.

51. Benson AB, D'Angelica MI, Abbott DE, et al. Hepatobiliary cancers, version 2.2021, NCCN clinical practice guidelines in oncology. J Natl Compr Canc Netw. 2021;19(5):541-565. doi:10.6004/jncen.2021.0022.

52. Golan T, Raitses-Gurevich M, Kelley RK, et al. Overall survival and clinical characteristics of BRCA-associated cholangiocarcinoma: a multicenter retrospective study. Oncologist. 2017;22 (7):804-810. doi:10.1634/theoncologist.2016-0415. 
53. Marabelle A, Fakih M, Lopez J, et al. Association of tumour mutational burden with outcomes in patients with advanced solid tumours treated with pembrolizumab: prospective biomarker analysis of the multicohort, open-label, phase 2 KEYNOTE-158 study. Lancet Oncol. 2020;21(10):1353-1365. doi:10.1016/ S1470-2045(20)30445-9.

54. Mosele F, Remon J, Mateo J, et al. Recommendations for the use of next-generation sequencing (NGS) for patients with metastatic cancers: a report from the ESMO Precision Medicine Working Group. Ann Oncol. 2020;31(11):1491-1505. doi:10.1016/j. annonc.2020.07.014.

55. Bekaii-Saab TS, Bridgewater J, Normanno N. Practical considerations in screening for genetic alterations in cholangiocarcinoma. Ann Oncol. 2021;32:1111-1126. doi:10.1016/j.annonc.20 21.04.012.

56. Lamarca A, Kapacee Z, Breeze M, et al. Molecular profiling in daily clinical practice: practicalities in advanced cholangiocarcinoma and other biliary tract cancers. J Clin Med. 2020;9(9):2854. doi:10.3390/jcm9092854.

57. Bridgewater J, Lopes A, Wasan H, et al. Prognostic factors for progression-free and overall survival in advanced biliary tract cancer. Ann Oncol. 2016;27(1):134-140. doi:10.1093/annonc/ mdv483.

58. Plentz RR, Malek NP. Systemic therapy of cholangiocarcinoma. Visc Med. 2016;32(6):427-430. doi:10.1159/000453084.

59. Sahai V, Catalano PJ, Zalupski MM, et al. Nab-paclitaxel and gemcitabine as first-line treatment of advanced or metastatic cholangiocarcinoma: a phase 2 clinical trial. JAMA Oncol. 2018;4(12):1707-1712. doi:10.1001/jamaoncol.2018. 3277.

60. Valle J, Wasan H, Palmer DH, et al. Cisplatin plus gemcitabine versus gemcitabine for biliary tract cancer. $N$ Engl J Med. 2010;362(14):1273-1281. doi:10.1056/NEJMoa0908721.

61. Okusaka T, Nakachi K, Fukutomi A, et al. Gemcitabine alone or in combination with cisplatin in patients with biliary tract cancer: a comparative multicentre study in Japan. Br J Cancer. 2010;103 (4):469-474. doi:10.1038/sj.bjc.6605779.

62. Shroff RT, Javle MM, Xiao L, et al. Gemcitabine, cisplatin, and nab-paclitaxel for the treatment of advanced biliary tract cancers: a phase 2 clinical trial. JAMA Oncol. 2019;5(6):824-830. doi:10.1001/jamaoncol.2019.0270.

63. Sakai D, Kanai M, Kobayashi S, et al. Randomized phase III study of gemcitabine, cisplatin plus S-1 (GCS) versus gemcitabine, cisplatin (GC) for advanced biliary tract cancer (KHBO1401-MITSUBA). Ann Oncol. 2018;29(supp1_8):viii205. doi:10.1093/annonc/mdy282.

64. Phelip JM, Desrame J, Edeline J, et al. 52P modified FOLFIRINOX versus CISGEM as first-line chemotherapy for advanced biliary tract cancer: results of AMEBICA PRODIGE 38 randomized phase II trial. Ann Oncol. 2020;31:S260-S261. doi:10.1016/j.annonc.2020.08.030.

65. Lamarca A, Palmer DH, Wasan HS, et al. Second-line FOLFOX chemotherapy versus active symptom control for advanced biliary tract cancer (ABC-06): a phase 3, open-label, randomised, controlled trial. Lancet Oncol. 2021;22(5):690-701. doi:10.1016/ S1470-2045(21)00027-9.

66. Yoo C, Kim KP, Kim I, et al. Liposomal irinotecan (nal-IRI) in combination with fluorouracil (5-FU) and leucovorin (LV) for patients with metastatic biliary tract cancer (BTC) after progression on gemcitabine plus cisplatin (GemCis): multicenter comparative randomized phase $2 \mathrm{~b}$ study (NIFTY). J Clin Oncol. 2021;39(Suppl 15):abstr 4006.

67. Hyder O, Marsh JW, Salem R, et al. Intra-arterial therapy for advanced intrahepatic cholangiocarcinoma: a multi-institutional analysis. Ann Surg Oncol. 2013;20(12):3779-3786. doi:10.1245/ s10434-013-3127-y.
68. Al-Adra DP, Gill RS, Axford SJ, Shi X, Kneteman N, Liau SS. Treatment of unresectable intrahepatic cholangiocarcinoma with yttrium-90 radioembolization: a systematic review and pooled analysis. Eur J Surg Oncol. 2015;41(1):120-127. doi:10.1016/j. ejso.2014.09.007.

69. Hong TS, Wo JY, Yeap BY, et al. Multi-institutional phase II study of high-dose hypofractionated proton beam therapy in patients with localized, unresectable hepatocellular carcinoma and intrahepatic cholangiocarcinoma. J Clin Oncol. 2016;34 (5):460-468. doi:10.1200/JCO.2015.64.2710.

70. Cercek A, Boerner T, Tan BR, et al. Assessment of hepatic arterial infusion of floxuridine in combination with systemic gemcitabine and oxaliplatin in patients with unresectable intrahepatic cholangiocarcinoma: a phase 2 clinical trial. JAMA Oncol. 2020;6(1):60-67. doi:10.1001/jamaoncol.2019.3718.

71. Piha-Paul SA, Oh DY, Ueno M, et al. Efficacy and safety of pembrolizumab for the treatment of advanced biliary cancer: results from the KEYNOTE-158 and KEYNOTE-028 studies. Int $J$ Cancer. 2020;147(8):2190-2198. doi:10.1002/ijc.33013.

72. Le DT, Durham JN, Smith KN, et al. Mismatch repair deficiency predicts response of solid tumors to PD-1 blockade. Science. 2017;357(6349):409-413. doi:10.1126/science.aan6733.

73. Pembrolizumab in biliary tract cancer. Available from: https:// ClinicalTrials.gov/show/NCT03260712. Accessed September 23, 2021.

74. Durvalumab or placebo in combination with gemcitabine/cisplatin in patients with 1st line advanced biliary tract cancer (TOPAZ1). Available from: https://ClinicalTrials.gov/show/ NCT03875235. Accessed September 23, 2021.

75. Nakamura H, Arai Y, Totoki Y, et al. Genomic spectra of biliary tract cancer. Nat Genet. 2015;47(9):1003-1010. doi:10.1038/ ng.3375.

76. Seedor RS, Hall MJ. Germline Testing in Biliary Tract Cancers. Gastrointestinal Cancers Symposium: ASCO Daily News; 2019.

77. Abou-Alfa GK, Macarulla T, Javle MM, et al. Ivosidenib in IDH1-mutant, chemotherapy-refractory cholangiocarcinoma (ClarIDHy): a multicentre, randomised, double-blind, placebocontrolled, phase 3 study. Lancet Oncol. 2020;21(6):796-807. doi:10.1016/S1470-2045(20)30157-1.

78. Abou-Alfa GK, Sahai V, Hollebecque A, et al. Pemigatinib for previously treated, locally advanced or metastatic cholangiocarcinoma: a multicentre, open-label, phase 2 study. Lancet Oncol. 2020;21(5):671-684. doi:10.1016/S1470-2045(20)30109-1.

79. Crispo F, Pietrafesa M, Condelli V, et al. IDH1 targeting as a new potential option for intrahepatic cholangiocarcinoma treatmentcurrent state and future perspectives. Molecules. 2020;25 (16):3754. doi:10.3390/molecules25163754.

80. Wick A, Bahr O, Schuler M, et al. Phase I assessment of safety and therapeutic activity of BAY1436032 in patients with IDH1mutant solid tumors. Clin Cancer Res. 2021;27(10):2723-2733. doi:10.1158/1078-0432.CCR-20-4256.

81. Furuse J, Goyal L, Meric-Bernstam F, et al. 116MO - efficacy, safety, and quality of life (QoL) with futibatinib in patients (pts) with intrahepatic cholangiocarcinoma (iCCA) harboring FGF. ESMO Asia Virtual Congress 2020. Ann Oncol. 2020;31: S1287-S1318.

82. Javle M, Lowery M, Shroff RT, et al. Phase II study of BGJ398 in patients with FGFR-altered advanced cholangiocarcinoma. J Clin Oncol. 2018;36(3):276-282. doi:10.1200/JCO. 2017.75.5009.

83. Javle MM, Roychowdhury S, Kelley RK, et al. Final results from a phase II study of infigratinib (BGJ398), an FGFR-selective tyrosine kinase inhibitor, in patients with previously treated advanced cholangiocarcinoma harboring an FGFR2 gene fusion or rearrangement. J Clin Oncol. 2021;39(3_suppl):265. doi:10.12 00/JCO.2021.39.3_suppl.265. 
84. Goyal L, Shi L, Liu LY, et al. TAS-120 overcomes resistance to ATP-competitive FGFR inhibitors in patients with FGFR2 fusionpositive intrahepatic cholangiocarcinoma. Cancer Discov. 2019;9 (8):1064-1079. doi:10.1158/2159-8290.CD-19-0182.

85. Doebele RC, Drilon A, Paz-Ares L, et al. Entrectinib in patients with advanced or metastatic NTRK fusion-positive solid tumours: integrated analysis of three phase 1-2 trials. Lancet Oncol. 2020;21(2):271-282. doi:10.1016/S1470-2045(19)30691-6.

86. Drilon A, Laetsch TW, Kummar S, et al. Efficacy of larotrectinib in TRK fusion-positive cancers in adults and children. $N$ Engl J Med. 2018;378(8):731-739. doi:10.1056/NEJMoa1714448.

87. Zhu AX, Meyerhardt JA, Blaszkowsky LS, et al. Efficacy and safety of gemcitabine, oxaliplatin, and bevacizumab in advanced biliary-tract cancers and correlation of changes in 18-fluorodeoxyglucose PET with clinical outcome: a phase 2 study. Lancet Oncol. 2010;11(1):48-54. doi:10.1016/S1470-2045(09)70333-X.

88. Lubner SJ, Mahoney MR, Kolesar JL, et al. Report of a multicenter phase II trial testing a combination of biweekly bevacizumab and daily erlotinib in patients with unresectable biliary cancer: a phase II Consortium study. J Clin Oncol. 2010;28 (21):3491-3497. doi:10.1200/JCO.2010.28.4075.

89. Iyer RV, Pokuri VK, Groman A, et al. A multicenter phase II study of gemcitabine, capecitabine, and bevacizumab for locally advanced or metastatic biliary tract cancer. Am J Clin Oncol. 2018;41(7):649-655. doi:10.1097/COC.0000000000000347.

90. Larsen FO, Markussen A, Diness LV, Nielsen D. Efficacy and safety of capecitabine, irinotecan, gemcitabine, and bevacizumab as second-line treatment in advanced biliary tract cancer: a phase II study. Oncology. 2018;94(1):19-24. doi:10.1159/000479970.

91. El-Khoueiry AB, Rankin C, Siegel AB, et al. S0941: a phase 2 SWOG study of sorafenib and erlotinib in patients with advanced gallbladder carcinoma or cholangiocarcinoma. $\mathrm{Br} J$ Cancer. 2014;110(4):882-887. doi:10.1038/bjc.2013.801.

92. Moehler M, Maderer A, Schimanski C, et al. Gemcitabine plus sorafenib versus gemcitabine alone in advanced biliary tract cancer: a double-blind placebo-controlled multicentre phase II AIO study with biomarker and serum programme. Eur J Cancer. 2014;50(18):3125-3135. doi:10.1016/j.ejca.2014.09.013.

93. Lee JK, Capanu M, O'Reilly EM, et al. A phase II study of gemcitabine and cisplatin plus sorafenib in patients with advanced biliary adenocarcinomas. Br J Cancer. 2013;109 (4):915-919. doi:10.1038/bjc.2013.432.

94. Valle JW, Wasan H, Lopes A, et al. Cediranib or placebo in combination with cisplatin and gemcitabine chemotherapy for patients with advanced biliary tract cancer (ABC-03): a randomised phase 2 trial. Lancet Oncol. 2015;16(8):967-978. doi:10.1016/S1470-2045(15)00139-4.

95. Santoro A, Gebbia V, Pressiani T, et al. A randomized, multicenter, phase II study of vandetanib monotherapy versus vandetanib in combination with gemcitabine versus gemcitabine plus placebo in subjects with advanced biliary tract cancer: the VanGogh study. Ann Oncol. 2015;26(3):542-547. doi:10.1093/ annonc/mdu576.

96. Sun W, Patel A, Normolle D, et al. A phase 2 trial of regorafenib as a single agent in patients with chemotherapy-refractory, advanced, and metastatic biliary tract adenocarcinoma. Cancer. 2019;125(6):902-909. doi:10.1002/cncr.31872.

97. Sohal DP, Mykulowycz K, Uehara T, et al. A phase II trial of gemcitabine, irinotecan and panitumumab in advanced cholangiocarcinoma. Ann Oncol. 2013;24(12):3061-3065. doi:10.1093/ annonc/mdt416.
98. Chen JS, Hsu C, Chiang NJ, et al. A KRAS mutation status-stratified randomized phase II trial of gemcitabine and oxaliplatin alone or in combination with cetuximab in advanced biliary tract cancer. Ann Oncol. 2015;26(5):943-949. doi:10.1093/annonc/mdv035.

99. Malka D, Cervera P, Foulon S, et al. Gemcitabine and oxaliplatin with or without cetuximab in advanced biliary-tract cancer (BINGO): a randomised, open-label, non-comparative phase 2 trial. Lancet Oncol. 2014;15(8):819-828. doi:10.1016/S14702045(14)70212-8.

100. Lee J, Park SH, Chang HM, et al. Gemcitabine and oxaliplatin with or without erlotinib in advanced biliary-tract cancer: a multicentre, open-label, randomised, phase 3 study. Lancet Oncol. 2012;13(2):181-188. doi:10.1016/S1470-2045(11)70301-1.

101. Vogel A, Kasper S, Bitzer M, et al. PICCA study: panitumumab in combination with cisplatin/gemcitabine chemotherapy in KRAS wild-type patients with biliary cancer-a randomised biomarker-driven clinical phase II AIO study. Eur J Cancer. 2018;92:11-19. doi:10.1016/j.ejca.2017.12.028.

102. Javle MM, Hainsworth JD, Swanton C, et al. Pertuzumab + trastuzumab for HER2-positive metastatic biliary cancer: preliminary data from MyPathway. $J$ Clin Oncol. 2017;35 (4_suppl):402. doi:10.1200/JCO.2017.35.4_suppl.402.

103. Jacobi O, Ross JS, Goshen-Lago T, et al. ERBB2 pathway in biliary tract carcinoma: clinical implications of a targetable pathway. Oncol Res Treat. 2021;44(1-2):20-27. doi:10.1159/00 0511919.

104. Ohba A, Morizane C, Ueno M, et al. Multicenter phase II study of trastuzumab deruxtecan (DS-8201) for HER2-positive unresectable or recurrent biliary tract cancer: HERB trial. J Clin Oncol. 2020;38 (15_suppl):TPS4654. doi:10.1200/JCO.2020.38.15_suppl.TPS4654.

105. Subbiah V, Lassen U, Elez E, et al. Dabrafenib plus trametinib in patients with BRAF(V600E)-mutated biliary tract cancer (ROAR): a phase 2, open-label, single-arm, multicentre basket trial. Lancet Oncol. 2020;21(9):1234-1243. doi:10.1016/S14702045(20)30321-1.

106. Goyal L, Zheng H, Yurgelun MB, et al. A phase 2 and biomarker study of cabozantinib in patients with advanced cholangiocarcinoma. Cancer. 2017;123(11):1979-1988. doi:10.1002/cncr.30571.

107. McNamara MG, Bridgewater JA, Palmer DH, et al. ABC-08: a phase $\mathrm{Ib}$, multi-centre, open-label study of a first-in-class nucleotide analogue NUC-1031 in combination with cisplatin in patients with locally advanced/metastatic biliary tract cancers. J Clin Oncol. 2018;36 (4_suppl):TPS544. doi:10.1200/JCO.2018.36.4_suppl.TPS544.

108. Mazzaferro V, El-Rayes BF, Droz Dit Busset M, et al. Derazantinib (ARQ 087) in advanced or inoperable FGFR2 gene fusion-positive intrahepatic cholangiocarcinoma. $\mathrm{Br} J$ Cancer. 2019;120(2):165-171. doi:10.1038/s41416-018-0334-0.

109. Javle MM, Oh D-Y, Ikeda M, et al. Results from TreeTopp: a randomized phase II study of the efficacy and safety of varlitinib plus capecitabine versus placebo in second-line (2L) advanced or metastatic biliary tract cancer (BTC). J Clin Oncol. 2020;38 (15 suppl):4597. doi:10.1200/JCO.2020.38.15 suppl.4597.

110. Peck J, Wei L, Zalupski M, O’Neil B, Villalona Calero M, BekaiiSaab T. HER2/neu may not be an interesting target in biliary cancers: results of an early phase II study with lapatinib. Oncology. 2012;82(3):175-179. doi:10.1159/000336488.

111. Tan E, Kim DW, Mehta R, et al. Phase II study of copanlisib in combination with gemcitabine and cisplatin in advanced cholangiocarcinoma. J Clin Oncol. 2020;38(4_suppl):556. doi:10.1200/ JCO.2020.38.4_suppl.556 


\section{Publish your work in this journal}

Cancer Management and Research is an international, peer-reviewed open access journal focusing on cancer research and the optimal use of preventative and integrated treatment interventions to achieve improved outcomes, enhanced survival and quality of life for the cancer patient.

The manuscript management system is completely online and includes a very quick and fair peer-review system, which is all easy to use. Visit http://www.dovepress.com/testimonials.php to read real quotes from published authors.

Submit your manuscript here: https://www.dovepress.com/cancer-management-and-research-journa| 